03.1

\title{
Управление детонационным горением посредством предварительной подготовки газовой смеси
}

\author{
(C) В.А. Левин ${ }^{1,2}$, Т.А. Журавская ${ }^{1,2}$ \\ ${ }^{1}$ Научно-исследовательский институт механики Московского государственного университета имени М.В. Ломоносова, \\ Москва, Россия \\ ${ }^{2}$ Центральный аэрогидродинамический институт им. профрессора Н.Е. Жуковского, \\ Жуковский, Московская обл., Россия \\ E-mail: zhuravskaya@imec.msu.ru
}

Поступило в Редакцию 14 октября 2019 г.

В окончательной редакции 14 октября 2019 г.

Принято к публикации 18 ноября 2019 г.

\begin{abstract}
С использованием детального кинетического механизма химического взаимодействия численно исследовано влияние предварительной подготовки стехиометрической водородно-воздушной смеси (разложения части молекулярного водорода и молекулярного кислорода на атомарные газы) на характеристики распространяющейся волны детонации. Выявлено, что указанная предварительная диссоциация приводит к существенному уменьшению поперечного размера детонационной ячейки при незначительном увеличении скорости распространения самоподдерживающейся волны, что позволяет использовать данную подготовку для предотвращения гашения детонации в каналах как с одиночным препятствием, так и с множественными барьерами.
\end{abstract}

Ключевые слова: плоский канал, детонация, барьер, сохранение/гашение детонационного горения.

DOI: 10.21883/PJTF.2020.04.49050.18074

Изучение возможности управления детонационным горением как в покоящейся газовой смеси, так и в сверхзвуковом потоке является одним из основных направлений исследования детонационных волн. В последнем случае большой интерес представляют механизмы стабилизации волны детонации и управления ее положением в высокоскоростном потоке, среди которых чаще всего используется подбор специальной формы канала. Подробный обзор работ, посвященных данной проблеме, представлен в [1]. Другим способом стабилизации и управления положением детонационной волны является добавление в газовый поток мелких инертных частиц [2,3] (за счет уменьшения скорости распространения детонации в смеси с подобными добавками). Наличие инертных частиц позволяет управлять детонационной волной и в покоящейся смеси. Так, в [4] численно исследовано ослабление и разрушение детонации помещенными в газ неподвижными частицами. В [5] экспериментально установлен факт полного гашения детонационного горения завесой из нереагирующих частиц пыли. Однако неменьший интерес представляют механизмы, препятствующие разрушению детонации. В настоящей работе исследуется возможность управления детонационным горением покоящейся стехиометрической водородновоздушной смеси с помощью предварительной подготовки газа.

Рассматривается распространение детонационной волны в покоящейся при нормальных условиях $\left(p_{0}=101325 \mathrm{~Pa}, \quad T_{0}=298 \mathrm{~K}\right)$ газовой смеси в полубесконечном плоском канале шириной $L$. Для инициирования детонации используется мгновенный однородный сверхкритический (достаточный для прямого инициирования детонации) подвод энергии в области, имеющей форму тонкого слоя, около закрытого торца канала. Изучается детонационное горение стехиометрической водородно-воздушной смеси, которая моделируется как смесь газов $\mathrm{H}_{2}, \mathrm{O}_{2}, \mathrm{~N}_{2}$ и $\mathrm{Ar}$ в молярном соотношении 42:21:78:1 соответственно, и подготовленной смеси, представляющей собой стехиометрическую водородно-воздушную смесь, в которой части молекулярного водорода $\left(\mathrm{H}_{2}\right)$ и молекулярного кислорода $\left(\mathrm{O}_{2}\right)$ предварительно разложены на атомы Н и О. В работе рассматриваются смеси со степенью предварительной диссоциации горючего и окислителя, равной $1 \%$ (далее смесь 1) и 1.5\% (далее смесь 2).

Система уравнений, описывающих плоское двумерное нестационарное течение невязкой многокомпонентной газовой смеси, имеет вид

$$
\begin{gathered}
\frac{\partial \rho}{\partial t}+\frac{\partial(\rho u)}{\partial x}+\frac{\partial(\rho v)}{\partial y}=0 \\
\frac{\partial(\rho u)}{\partial t}+\frac{\partial\left(\rho u^{2}+p\right)}{\partial x}+\frac{\partial(\rho u v)}{\partial y}=0, \\
\frac{\partial(\rho v)}{\partial t}+\frac{\partial(\rho v u)}{\partial x}+\frac{\partial\left(\rho v^{2}+p\right)}{\partial y}=0,
\end{gathered}
$$



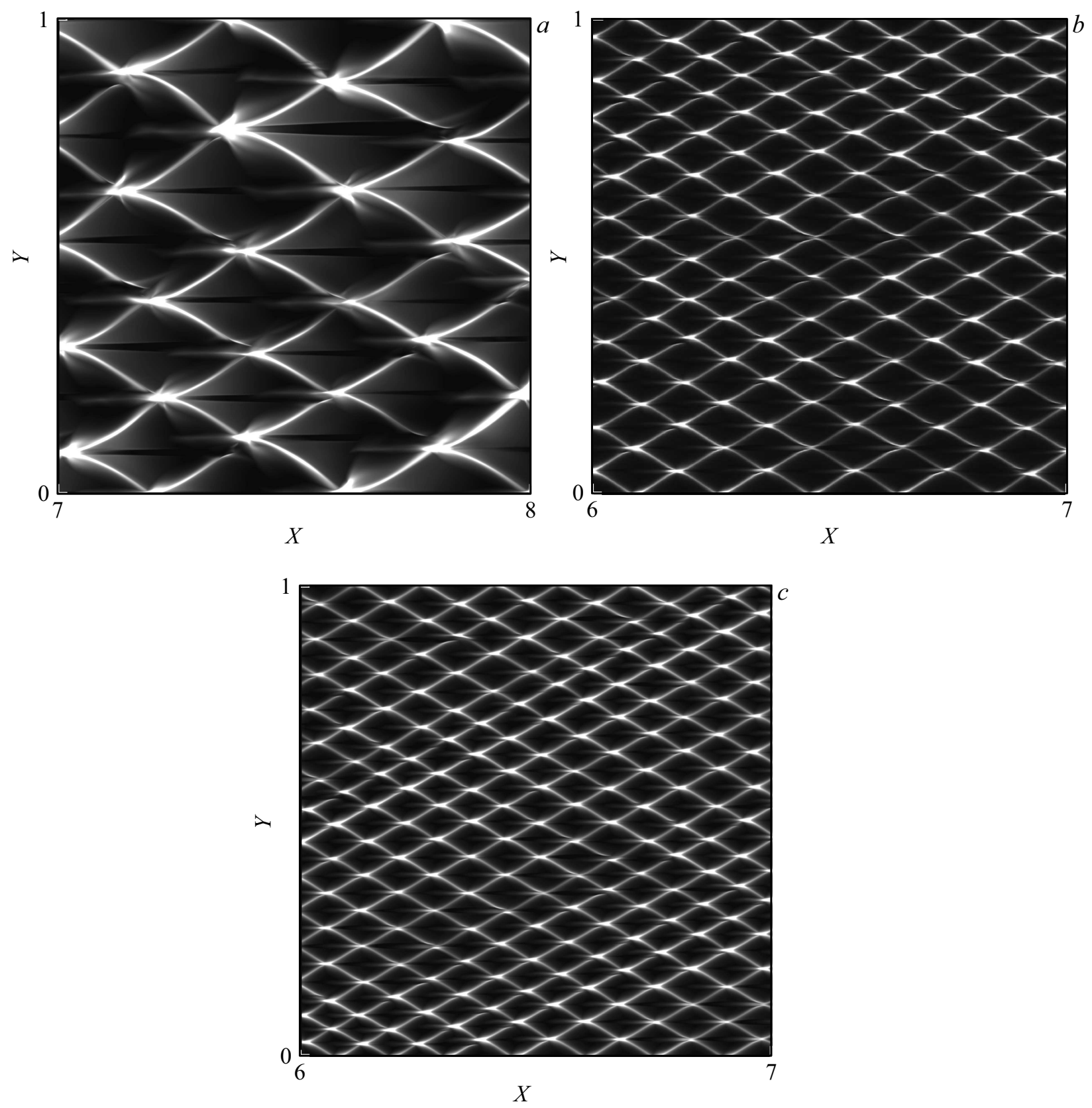

Рис. 1. Ячеистая структура детонационной волны, распространяющейся в плоском канале. $a-$ стехиометрическая водородновоздушная смесь; $b$ - предварительно подготовленная смесь $1 ; c-$ предварительно подготовленная смесь 2 . Здесь и далее $X=x / L, Y=y / L$, где $L-$ ширина канала. Волна распространяется слева направо.

$$
\begin{gathered}
\frac{\partial\left(\rho\left(u^{2}+v^{2}\right) / 2+\rho h-p\right)}{\partial t}+\frac{\partial\left(\rho u\left(\left(u^{2}+v^{2}\right) / 2+h\right)\right)}{\partial x} \\
+\frac{\partial\left(\rho v\left(\left(u^{2}+v^{2}\right) / 2+h\right)\right)}{\partial y}=0, \\
\frac{\partial\left(\rho n_{i}\right)}{\partial t}+\frac{\partial\left(\rho u n_{i}\right)}{\partial x}+\frac{\partial\left(\rho v n_{i}\right)}{\partial y}=\rho \omega_{i} .
\end{gathered}
$$

Здесь $x$ и $y$ - продольная и поперечная декартовы координаты, $u$ и $v$ - соответствующие компоненты скорости, $t-$ время, $\rho, p$ и $h-$ плотность, давление и удельная энтальпия смеси, $n_{i}$ и $\omega_{i}-$ удельные концентрация и скорость образования $i$-го компонента смеси.

Уравнения состояния горючей смеси, рассматриваемой как совершенный газ, имеют следующий вид:

$$
p=\rho R_{0} T \sum_{i} n_{i}, \quad h=\sum_{i} n_{i} h_{i}(T) .
$$

Здесь $T$ - температура, $R_{0}-$ универсальная газовая постоянная. Зависимости парциальных энтальпий от 

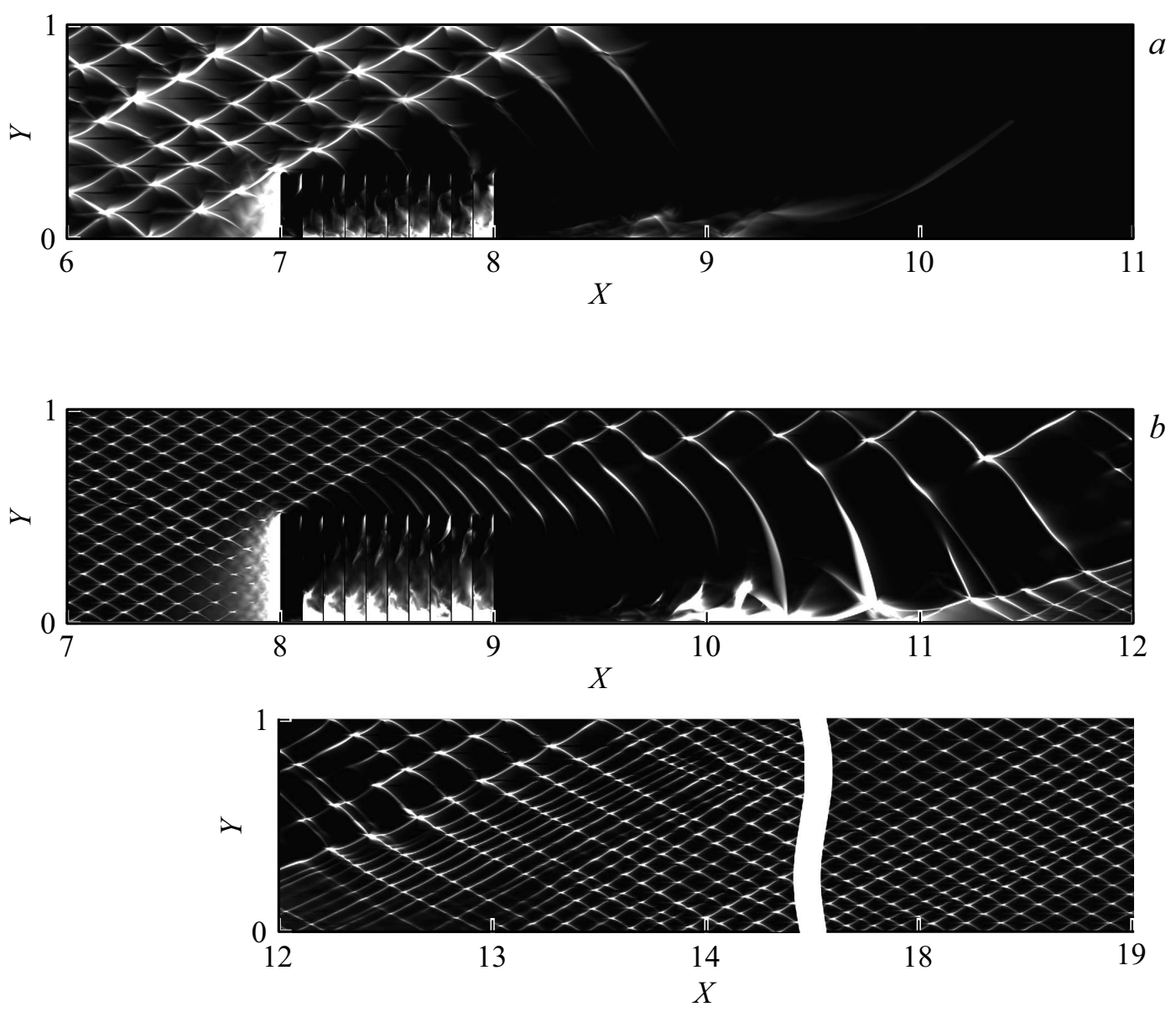

Рис. 2. Распространение детонационной волны в плоском канале с областью препятствий (барьеров). $a-$ разрушение детонации в стехиометрической водородно-воздушной смеси; $b-$ сохранение детонационного горения в предварительно подготовленной смеси 1. Волна распространяется слева направо.

температуры $h_{i}(T)$ определяются по приведенным энергиям Гиббса соответствующих компонентов смеси [6].

Для описания химического взаимодействия используется модифицированный детальный кинетический механизм окисления водорода, предложенный в [7].

Решение уравнений газовой динамики совместно с уравнениями детальной химической кинетики было проведено конечно-разностным методом, основанным на схеме Годунова. Для численного моделирования использовался разработанный авторами и апробированный ранее [1-3] программный комплекс, в котором реализовано гибридное распараллеливание расчетов MPI/OpenMP. Моделирование проведено при шаге разбиения расчетной сетки $\Delta=5 \mu \mathrm{m}$, обеспечивающем корректное разрешение структуры детонационной волны. Исследование выполнено с использованием оборудования Центра коллективного пользования сверхвысокопроизводительными вычислительными ресурсами МГУ им. М.В. Ломоносова $[8]$.

В результате энергоподвода в газе инициируется плоская детонационная волна. Однако фронт вол- ны постепенно искривляется, возникают поперечные волны, в канале формируется детонационная волна с устойчивой ячеистой структурой [9]. Численное моделирование показало, что предварительная подготовка смеси приводит к существенному уменьшению поперечного размера детонационной ячейки (рис. 1) и незначительному увеличению скорости распространения самоподдерживающейся волны детонации. Так, в рассмотренных смесях 1 и 2 (рис. $1, b, c$ ) детонационная ячейка меньше ячейки в неподготовленной смеси (рис. 1,a) более чем в 2 и 3 раза соответственно, при этом скорость распространения волны увеличивается в результате предварительной диссоциации не более чем на $1 \%$. Изучение структуры плоской одномерной стационарной детонационной волны (структуры детонации Зельдовича-Неймана-Деринга) в указанных смесях показало, что предварительная подготовка увеличивает скорость детонации Чепмена-Жуге не более чем на $1.12 \%$, при этом протяженность зоны индукции существенно уменьшается. Интересно отметить, что подобное влияние предварительная частичная диссоциация 
оказывает на характеристики детонационной волны и в случае водородно-кислородной смеси, разбавленной аргоном.

Установленные особенности детонационного горения новой смеси, получаемой в результате предварительной частичной диссоциации $\mathrm{H}_{2}$ и $\mathrm{O}_{2}$, позволяют использовать подготовку для управления детонацией в каналах с препятствиями.

Рассмотрено взаимодействие сформированной ячеистой детонационной волны с поперечным бесконечно тонким неразрушающимся одиночным препятствием (барьером), расположенным в канале. Известно, что взаимодействие детонационной волны с препятствием, высота которого превышает некоторое (критическое) значение, зависящее от ширины канала, приводит к срыву детонации [10]. В результате численного моделирования установлено, что критическая высота препятствия для подготовленной смеси превышает критическую высоту для неподготовленной при прочих равных условиях. Таким образом, подготовка газа может использоваться для предотвращения разрушения волны детонации расположенным в канале барьером. Более того, при увеличении высоты препятствия в ряде случаев достаточным условием для сохранения детонационного горения является увеличение степени предварительной диссоциации газов.

Исследовано взаимодействие распространяющейся в плоском канале ячеистой детонационной волны с областью барьеров, расположенной на одной из его стенок. Подобная область может рассматриваться как простая модель пористой вставки на внутренней поверхности канала (например, покрытой стальной ватой), используемой для ослабления и гашения детонационного горения $[11,12]$. Численное моделирование показало, что результат взаимодействия волны с препятствиями зависит от протяженности области $L_{b}$, высоты барьеров $H_{b}$ и расстояния между соседними барьерами $\Delta L_{b}$.

Установлено, что при фиксированных параметрах области $L_{b}$ и $\Delta L_{b}$ существует критическая высота барьеров, при превышении которой препятствия гасят детонационное горение газовой смеси. Получено, что, как и при одиночном препятствии, критическая высота барьеров в случае подготовленной смеси существенно превышает критическую высоту для неподготовленной (рис. 2), что указывает на возможность использования предварительной частичной диссоциации для предотвращения разрушения волны детонации в канале с подобными вставками. Так, установлено, что в канале шириной $L=1 \mathrm{~cm}$ препятствия высотой $H_{b}=3 \mathrm{~mm}$ гасят детонационное горение в неподготовленной смеси (рис. 2,a), в то время как взаимодействие волны с областью барьеров высотой $H_{b}=5 \mathrm{~mm}$ в подготовленной смеси 1 не приводит к разрушению детонации (рис. 2,b). Представленный численный аналог следа детонационной волны в последнем случае (рис. 2,b) показывает, что при движении вдоль области барьеров происходит ослабление поперечных волн и увеличение детонационной ячейки, что согласуется с данными экспериментов [11]. После прохождения препятствий в случае сохранения детонации ячеистая структура волны восстанавливается с течением времени (рис. 2, $b$ ).

Таким образом, проведенное численное моделирование показало, что предварительная частичная диссоциация части молекулярного водорода и молекулярного кислорода в водородно-воздушной смеси приводит к существенному уменьшению размера ячейки детонационной волны при незначительном увеличении ее скорости, что делает возможным использование указанной подготовки для предотвращения гашения детонационного горения в плоских каналах как с одиночным препятствием, так и с множественными барьерами.

\section{Финансирование работы}

Работа выполнена при поддержке Министерства образования и науки РФ (договор 14.G39.31.0001 от 13.02.2017 г.). Изучение гашения детонации в каналах с барьерами проведено при поддержке Российского фонда фундаментальных исследований (проекты № 16-29-01092, 18-01-00883).

\section{Конфликт интересов}

Авторы заявляют, что у них нет конфликта интересов.

\section{Список литературы}

[1] Журавская Т.А., Левин В.А. // Изв. РАН. Механика жидкости и газа. 2016. № 4. С. 120-129.

[2] Левин В.А., Журавская Т.А. // Письма в ЖТФ. 2017. Т. 43. B. 6. C. 78-85. DOI: 10.21883/PJTF.2017.06.44407.16560

[3] Левин В.А., Журавская Т.A. // Тр. Матем. ин-та им. В.А. Стеклова. 2018. Т. 300. С. 123-134. https://doi.org/10.1134/S0371968518010090

[4] Bedarev I.A., Fedorov A.V. // J. Phys.: Conf. Ser. 2017. V. 894. N 1. P. 012008.

[5] Васильев А.А., Пинаев А.В., Трубицын А.А., Грачёв А.Ю., Троцюк А.В., Фомин П.А., Трилис А.В. // Физика горения и взрыва. 2017. Т. 53. № 1. С. 11-18.

[6] Термодинамические свойства индивидуальных веществ / Отв. ред. В.П. Глушко. М.: Наука, 1978. Т. І. 495 с.

[7] Bezgin L.V., Kopchenov V.I., Sharipov A.S., Titova N.S., Starik A.M. // Combust. Sci. Technol. 2013. V. 185. N 1. P. 62 94. https://doi.org/10.1080/00102202.2012.709562

[8] Воеводин Вл.В., Жуматий С.А., Соболев С.И., Антонов А.С., Брызгалов П.А., Никитенко Д.А., Стеббанов К.С., Воеводин Вад.В. // Открытые системы. 2012. № 7. C. $36-39$.

[9] Lee J.H.S. The detonation phenomenon. Cambridge: Cambridge University Press, 2008. 400 p. https://doi.org/10.1017/CBO9780511754708 
[10] Журавская Т.А. // Изв. РАН. Механика жидкости и газа. 2007. № 6. С. 135-143.

[11] Radulescu M.I., Lee J.H.S. // Combust. Flame. 2002. V. 131. N 1-2. P. 29-46.

http://dx.doi.org/10.1016/S0010-2180(02)00390-5

[12] Bivol G.Yu., Golovastov S.V., Golub V.V. // Shock Waves. 2018. V. 28. N 5. P. 1011-1018.

https://doi.org/10.1007/s00193-018-0831-3 